\title{
BIOMASSA E ATIVIDADES MICROBIANAS EM SOLO SOB PASTAGEM COM DIFERENTES LOTAÇÕES DE OVINOS ${ }^{(1)}$
}

\author{
Martha Regina Lucizano Garcia ${ }^{(2)}$ \& Ely Nahas ${ }^{(3)}$
}

\begin{abstract}
RESUMO
Os efeitos da lotação de animais na produção de ovinos têm sido bastante estudados. No entanto, informações sobre seus efeitos na biomassa e nas atividades microbianas e, em conseqüência, na fertilidade do solo de pastagens são escassas. Neste trabalho, os efeitos da lotação de ovinos (LO) na biomassa e nas atividades microbianas responsáveis pela transformação dos compostos do $\mathrm{C}$ e $\mathrm{N}$ em solo de clima subtropical foram avaliados. As amostras de solo foram coletadas nas camadas de 0-10 e 10-20 cm de pastos com baixa LO ( 5 animais ha-1), alta LO (40-50 animais ha-1) e com ausência de animais, em um delineamento inteiramente casualizado em parcelas subdivididas, com seis repetições. Os maiores valores de biomassa microbiana e das atividades respiratória, nitrificante e enzimática (urease e protease) foram encontrados nos solos dos pastos com baixa LO. Estes pastos também acumularam as maiores quantidades de matéria orgânica e $\mathbf{N}$ total. Essas variáveis foram reduzidas nos pastos sem animais ou com alta LO. Vegetação descontínua e intensa mineralização podem ter acarretado a diminuição dessas variáveis nos pastos com alta LO. Alta correlação foi obtida entre matéria orgânica, $\mathrm{C}$ orgânico e $\mathrm{N}$ total com as quantidades de biomassa microbiana e a atividade enzimática. A camada de $\mathbf{0}-\mathbf{1 0} \mathrm{cm}$ apresentou valores maiores das variáveis estudadas do que os encontrados na camada de $10-20 \mathrm{~cm}$.
\end{abstract}

Termos de indexação: atividade biológica, $\mathrm{CO}_{2}$, enzimas, matéria orgânica.

\footnotetext{
(1) Recebido para publicação em março de 2006 e aprovado em dezembro de 2006.

${ }^{(2)}$ Doutoranda do Programa de Pós-Graduação em Microbiologia, Faculdade de Ciências Agrárias e Veterinárias, Universidade Estadual de São Paulo - FCAV/UNESP. Rod. Prof. Paulo Donato Castellane s/n, CEP 14884-900 Jaboticabal (SP). E-mail: martharlg@yahoo.com.br

(3) Professor Titular do Departamento de Produção Vegetal, FCAV/UNESP. E-mail: enahas@fcav.unesp.br.
} 


\title{
SUMMARY: BIOMASS AND MICROBIAL ACTIVITY IN PASTURE SOIL UNDER DIFFERENT SHEEP GRAZING PRESSURE
}

\begin{abstract}
The effect of grazing pressure in sheep production has been studied, but not in relation to soil microbiological parameters or the consequences on soil fertility. The effect of grazing pressure (GP) by sheep on biomass and microbial activity related to $C$ and $N$ compounds cycling in subtropical region soil was studied. Soil samples were collected from the $0-10 \mathrm{~cm}$ and 10-20 cm layers in pastures with low GP (5 animals ha-1), high GP (40-50 animals $\left.\mathrm{ha}^{-1}\right)$ and in absence of animals, in a completely randomized design with 6 replicates. The highest values of microbial biomass and respiratory, nitrifying and enzymatic (urease and protease) activities were found in pasture soil with low GP. This pasture also accumulated highest amounts of organic matter and total $N$. These variables decreased in pastures without animals or with high GP. Discontinuous vegetation and intense mineralization may have caused this reduction in the soils with pastures under high GP. It was observed a high correlation between organic matter, organic $C$ and total $N$ with the amounts of microbial biomass and enzymatic activity. The values of the variables under study were higher in the $0-10 \mathrm{~cm}$ than in the 10-20 cm layer.
\end{abstract}

Index terms: biological activity, enzymes, $\mathrm{CO}_{2}$, organic matter.

\section{INTRODUÇÃO}

A taxa de lotação dos ovinos ( $\mathrm{n}^{0}$ animais ha-1) é influenciada pela capacidade de suporte da gramínea, pelos fatores ambientais, pela fertilidade do solo e pela condução do manejo. O manejo do pasto deve minimizar os impactos decorrentes das limitações das forrageiras, sendo necessário ajustar a lotação para evitar problemas de sub ou superpastejo (Silva Sobrinho, 2001). Assim, a produção de ovinos em pastagem com capim Tanzânia foi maior com taxa de lotação de 11 animais ha-1 do que com 44 animais ha ${ }^{-1}$ (Castro et al., 2003).

O suprimento mais importante de nutrientes para as pastagens provém das excreções dos animais, na forma de esterco e de urina (Haynes \& Williams, 1999). Uma única excreção equivale a $1.200 \mathrm{~g}$ de esterco e $200 \mathrm{~mL}$ de urina, retornando 3,4-3,6 e 0,3-1,4\%, respectivamente, do $\mathrm{N}$ consumido diariamente por ovinos (Allen et al., 1996). Os excrementos de ovinos apresentam baixa relação $\mathrm{C}: \mathrm{N}$, permitindo rápida mineralização e, ou, mantendo a disponibilidade dos nutrientes no solo. Esses materiais acumulam-se no solo, aumentando a quantidade de matéria orgânica e estimulando o metabolismo microbiano (Carran \& Theobald, 2000). Com o aumento da disponibilidade de substratos orgânicos e nutrientes, a atividade das enzimas protease, desaminase e urease e o $\mathrm{C}$ da biomassa microbiana foram estimulados (Cameron, 1999; Bol et al., 2003). Contudo, o impacto da taxa de lotação de ovinos nos microrganismos e de suas atividades não tem sido devidamente estudado no solo sob pastos.

O aumento da biomassa microbiana tem sido relacionado ao aumento da matéria orgânica no solo
(Rezende et al., 2004). A atividade heterotrófica da biomassa pode ser avaliada pela produção de $\mathrm{CO}_{2}$, sendo a quantidade de $\mathrm{C}$ liberado indicativa do $\mathrm{C}$ lábil ou prontamente metabolizável do solo (GamaRodrigues, 1999). Em adição a essas variáveis, a nitrificação e as características químicas do solo são utilizadas como indicativos de mudanças da sua qualidade (Stamatiadis et al., 1999). Por exemplo, a aplicação de esterco bovino ao solo resultou em aumento de 20 vezes da atividade nitrificante, em relação ao controle sem esterco (Mueller et al., 2003).

O objetivo deste estudo foi avaliar o efeito da taxa de lotação de ovinos na biomassa e nas atividades microbianas responsáveis pela transformação dos compostos dos ciclos do $\mathrm{C}$ e $\mathrm{N}$ em solo de pastos de clima subtropical sob pastagem.

\section{MATERIAL E MÉTODOS}

O experimento foi conduzido nos meses de janeirofevereiro de 2005 na Faculdade de Ciências Agrárias e Veterinárias/UNESP - Jaboticabal (SP), geograficamente definida pelas coordenadas de $21^{\circ} 18^{\prime} 22$ " de latitude sul e $48^{\circ} 18$ ' 58 " de longitude oeste de Greenwich, altitude de $595 \mathrm{~m}$ e clima subtropical, com chuvas de verão e inverno seco, segundo a classificação de Köppen. A precipitação pluviométrica anual é de $1.230 \mathrm{~mm}$, com temperaturas anuais variando de 12,8 a $32,7^{\circ} \mathrm{C}$ e média anual de $22^{\circ} \mathrm{C}$, sendo a umidade relativa do ar de $70 \%$. Foram utilizados pastos de aproximadamente 1 ha cada, com baixa lotação de ovinos (LO); 5 animais ha ${ }^{-1}$ (reprodutores), alta LO; 40-50 animais ha-1 (animais de cria e recria); e controle, sem animais pastejando. 
Foram utilizados ovinos de sangue $50 \%$ Ideal + $50 \%$ Ile de France e as raças Santa Inês e Morada Nova, com idade média variando de seis meses a cinco anos. A área vem sendo usada para pasto de ovinos há aproximadamente 23 anos. Há nove anos o capim Coast Cross foi substituído pelo Tifton 85 (Cynodon spp. cv. Tifton-85). As amostras do solo Latossolo Vermelho eutrófico (Embrapa, 1999) foram coletadas nas camadas de 0-10 e 10-20 cm, utilizando-se trado holandês. Em cada parcela foram retiradas seis amostras simples, que foram reunidas para formar uma amostra composta. As amostras foram peneiradas ( $2 \mathrm{~mm}$ ) e divididas em duas frações: uma para as análises microbianas, a qual foi mantida em geladeira até o momento de uso, e a outra para determinações químicas, a qual foi seca ao ar (TFSA) e conservada em temperatura ambiente.

O C e o $\mathrm{N}$ da biomassa microbiana do solo foram quantificados pelos métodos de Vance et al. (1987) e Brookes et al. (1985), respectivamente. As amostras de solo (10 g) foram submetidas à fumigação com clorofórmio por um período de $24 \mathrm{~h}$ e posterior extração com $50 \mathrm{~mL}$ de solução de $\mathrm{K}_{2} \mathrm{SO}_{4} 0,5 \mathrm{~mol} \mathrm{~L}^{-1}$. Os extratos foram filtrados em papel-filtro Whatman 42 . Amostras não-fumigadas foram extraídas da mesma forma. A quantidade de $\mathrm{C}$ foi determinada após digestão de $8 \mathrm{~mL}$ do filtrado com $\mathrm{K}_{2} \mathrm{CR}_{2} \mathrm{O}_{7}$ e titulação do excesso de $\mathrm{K}_{2} \mathrm{Cr}_{2} \mathrm{O}_{7}$ com sulfato ferroso amoniacal. $\mathrm{O} \mathrm{N}$ da biomassa microbiana foi determinado nos mesmos extratos obtidos para determinação do $\mathrm{C}$ da biomassa microbiana, utilizando-se o método de Kjeldahl. As diferenças entre as amostras fumigadas e não-fumigadas foram multiplicadas pelo fator de correção 2,64, para cálculo do $\mathrm{C}$ da biomassa microbiana (Vance et al., 1987), e divididas por 0,54, para cálculo do $\mathrm{N}$ da biomassa microbiana (Brookes et al., 1985).

A atividade respiratória do solo foi determinada em frascos de 2,5 L com $100 \mathrm{~g}$ de solo e dois frascos, um com $10 \mathrm{~mL}$ de água destilada e outro com $10 \mathrm{~mL}$ de $\mathrm{NaOH} 0,5 \mathrm{~mol} \mathrm{~L}^{-1}$. Após incubação por sete dias a $28{ }^{\circ} \mathrm{C}$, o $\mathrm{NaOH}$ foi titulado com $\mathrm{HCl} 0,5 \mathrm{~mol} \mathrm{~L}^{-1}$
(Rezende et al., 2004). A atividade nitrificante foi determinada incubando-se o solo úmido com e sem adição de $160 \mathrm{mg} \mathrm{g}^{-1}$ de $\mathrm{N}\left(\left(\mathrm{NH}_{4}\right)_{2} \mathrm{SO}_{4}\right)$ no solo seco, por 21 dias a $30^{\circ} \mathrm{C}$ (Schmidt \& Belser, 1994). A extração do nitrato foi feita com $50 \mathrm{~mL}$ de solução $\mathrm{KCl} 1 \mathrm{~mol} \mathrm{~L}^{-1}$, e a análise, por titulação (Keeney \& Nelson, 1982).

A atividade da urease foi determinada incubandose 2,0 g de solo úmido, com 0,2 $\mathrm{mL}$ de tolueno, $2,0 \mathrm{~mL}$ de tampão fosfato $\left(\mathrm{KH}_{2} \mathrm{PO}_{4}\right) \quad 0,1 \mathrm{~mol} \mathrm{~L}^{-1} \mathrm{pH} 6,7 \mathrm{e}$ $1,0 \mathrm{~mL}$ de uréia $10 \%(\mathrm{n} / \mathrm{v})$ por três horas a $37^{\circ} \mathrm{C}(\mathrm{Mc}$ Garity \& Myers, 1967). A atividade foi expressa em $\mathrm{mg} \mathrm{g}^{-1}$ de $\mathrm{NH}_{4}-\mathrm{N}$ no solo seco. Para a atividade da protease, incubou-se 1,0 g de solo úmido com $2,5 \mathrm{~mL}$ de solução de caseína $1 \%$ (p/v) em tampão tris- $\mathrm{HCl}$ $0,1 \mathrm{~mol} \mathrm{~L}^{-1} \mathrm{pH} 8,1$, por uma hora a $52{ }^{\circ} \mathrm{C}$ (Nannipieri et al., 1979). A atividade foi expressa em $\mathrm{mg} \mathrm{g}^{-1} \mathrm{de}$ tirosina no solo seco.

A biomassa microbiana e a atividade enzimática foram determinadas em amostras de solo com teor de umidade equilibrado em $60 \%$ da capacidade de retenção de água.

O C orgânico foi determinado pelo método de oxidação por dicromato de potássio - ácido sulfúrico (Sims \& Haby, 1971). A matéria orgânica foi determinada em mufla (De Boer et al., 1988) e o N total, pelo método de Bremmer \& Mulvaney (1982), com a digestão das amostras de solo com $\mathrm{H}_{2} \mathrm{SO}_{4}$. A composição química do solo foi determinada segundo Van Raij \& Quaggio (1983) (Quadro 1).

$\mathrm{O}$ delineamento experimental foi o inteiramente casualizado, em esquema de parcelas subdivididas, com seis repetições. Nas parcelas foram consideradas as taxas de lotação e, nas subparcelas, as profundidades de amostragem do solo. Os resultados foram submetidos à análise de variância, aplicandose o teste F. O teste de Tukey $(p<0,05)$ foi empregado para comparação de médias. Também foram estimados os coeficientes de correlação entre as variáveis, pelo coeficiente de correlação de Pearson. Para análise estatística, foi utilizado o programa SAS (1990).

Quadro 1. Caracterização química do solo dos pastos nas diferentes profundidades

\begin{tabular}{|c|c|c|c|c|c|c|c|c|c|c|c|}
\hline Pasto & Profundidade & pH $\mathrm{CaCl}_{2}$ & MO & $\mathbf{P}$ & $\mathbf{K}^{+}$ & $\mathrm{Ca}^{2+}$ & $\mathbf{M g}^{2+}$ & $\mathbf{H}+\mathbf{A l}$ & SB & $\mathbf{T}$ & $\mathbf{V}$ \\
\hline \multirow{3}{*}{ Controle } & $\mathrm{cm}$ & & $\mathrm{g} \mathrm{dm}-3$ & $\mathrm{mg} \mathrm{dm}^{-3}$ & \multicolumn{6}{|c|}{$-\mathrm{mmol}_{\mathrm{c}} \mathrm{dm}^{-3}$} & $\%$ \\
\hline & $0-10$ & 5,3 & 24 & 70 & 3,6 & 32 & 19 & 28 & 54,6 & 82,6 & 66 \\
\hline & $10-20$ & 5,2 & 22 & 32 & 2,7 & 24 & 16 & 28 & 42,7 & 70,7 & 60 \\
\hline Baixa & $0-10$ & 5,5 & 45 & 232 & 8,5 & 48 & 25 & 31 & 81,5 & 112,5 & 72 \\
\hline Lotação & $10-20$ & 5,4 & 30 & 270 & 8,9 & 38 & 21 & 31 & 67,9 & 98,9 & 69 \\
\hline Alta & $0-10$ & 5,3 & 23 & 12 & 1,1 & 26 & 12 & 25 & 39,1 & 64,1 & 61 \\
\hline Lotação & $10-20$ & 5,0 & 18 & 7 & 0,6 & 15 & 7 & 25 & 22,6 & 47,6 & 47 \\
\hline
\end{tabular}

SB: soma de bases; T: capacidade de troca catiônica; V: saturação por bases. 


\section{RESULTADOS E DISCUSSÃO}

As quantidades de carbono (CBM) e de N (NBM) da biomassa microbiana de solo pastejado com diferentes lotações de ovinos (LO) variaram de 154,15 a $459,59 \mu \mathrm{g} \mathrm{g}^{-1}$ de C no solo seco (Figura 1a) e de 2,49 a $6,15 \mu \mathrm{g} \mathrm{g}^{-1}$ de N no solo seco (Figura 1b), respectivamente. Observou-se aumento significativo (Tukey, $\mathrm{p}<0,05$ ) de 1,3 a 2,7 vezes do CBM e de 0,6 a 1,2 vez do NBM da camada de $0-10 \mathrm{~cm}$, comparativamente à de $10-20 \mathrm{~cm}$. Os teores de CBM e de NBM nos pastos com baixa LO foram superiores ( $p<0,05)$ aos encontrados nos demais pastos. Os maiores teores de BM nos pastos com animais, em relação ao controle, mostram efeito diferenciado, resultante, possivelmente, da excreção dos animais. Esse efeito foi relatado por Ghani et al. (2003), quando compararam solos com e sem pastejo animal, e por Saviozzi et al. (2001), que verificaram que solos da Itália sob pastagem apresentaram maior percentagem de CBM que os solos sob floresta e cultivo agrícola. Da mesma forma, Holt (1997) reportou diminuição de 24-51 \% dos teores de CBM de pastagens da Austrália com alta lotação de bovinos, em relação aos de baixa lotação.

$\mathrm{O}$ efeito da profundidade de amostragem do solo nas atividades respiratória e nitrificante mostrou tendência semelhante à variação do $\mathrm{CBM}$, verificandose aumento significativo da produção de $\mathrm{CO}_{2}$ de 2 a 13 vezes (Figura 2) e de $\mathrm{NO}_{3}{ }^{-}$de 1,5 a 2,1 vezes (Figura 3) na camada de $0-10 \mathrm{~cm}$ em relação à de $10-20 \mathrm{~cm}$. Esse aumento pode ser devido ao efeito da cobertura vegetal sobre a estruturação do solo e do acúmulo de matéria orgânica (Fialho et al., 1991). As atividades respiratória (Figura 2) e nitrificante (Figura 3) foram maiores no solo dos pastos com baixa LO que do controle ou dos pastos com alta LO. Esses resultados podem ser atribuídos à melhor qualidade do solo superficial do pasto com baixa LO (Quadro 1), favorecendo o crescimento e metabolismo microbiano. Principalmente o conteúdo de matéria orgânica do solo tem sido relacionado ao aumento da atividade respiratória (Ross et al., 1995), efeito este que pode ser confirmado pela correlação significativa e positiva entre a matéria orgânica e as atividades respiratória $\left(\mathrm{r}=0,81^{* * *}\right)$ e nitrificante $\left(\mathrm{r}=0,87^{* * *}\right)$ (Quadro 3). A correlação significativa e positiva entre o CBM e as atividades respiratória $\left(r=0,88^{* * *}\right)$ e nitrificante $\left(\mathrm{r}=0,75^{* * *}\right)$ indica que esse efeito foi proporcionado por maior biomassa microbiana nos pastos com baixa LO. Em adição, a correlação significativa entre o CBM e as atividades proteolítica $\left(\mathrm{r}=0,92^{* * *}\right)$ e ureolítica $\left(\mathrm{r}=0,90^{* * *}\right)$ (Quadro 3) indica que essa população apresentou alta atividade de mineralização do $\mathrm{C} \mathrm{e} \mathrm{N}$.
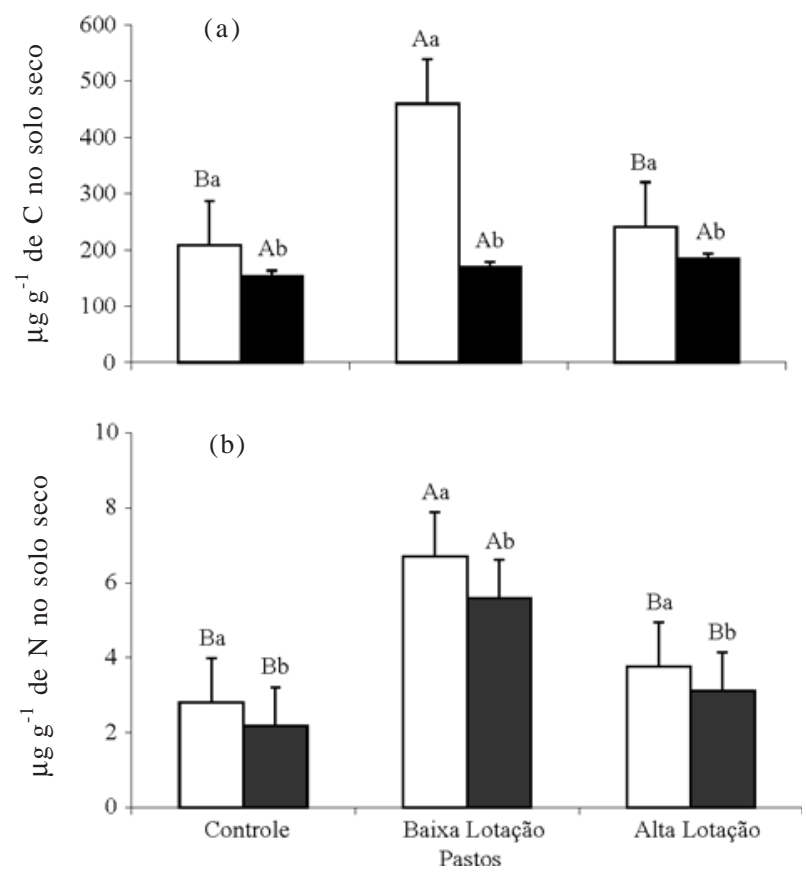

Figura 1. Carbono da biomassa microbiana (a) e nitrogênio da biomassa microbiana (b) encontrados nas camadas de 0-10 ( $\square$ ) e 10-20 cm ( $\square$ ) do solo pastejado por ovinos. Médias seguidas de mesma letra, minúscula (profundidade) e maiúscula (pastos), dentro de cada variável, não diferem entre si pelo teste de Tukey a $5 \%$. As barras representam o erro padrão $(n=15)$.

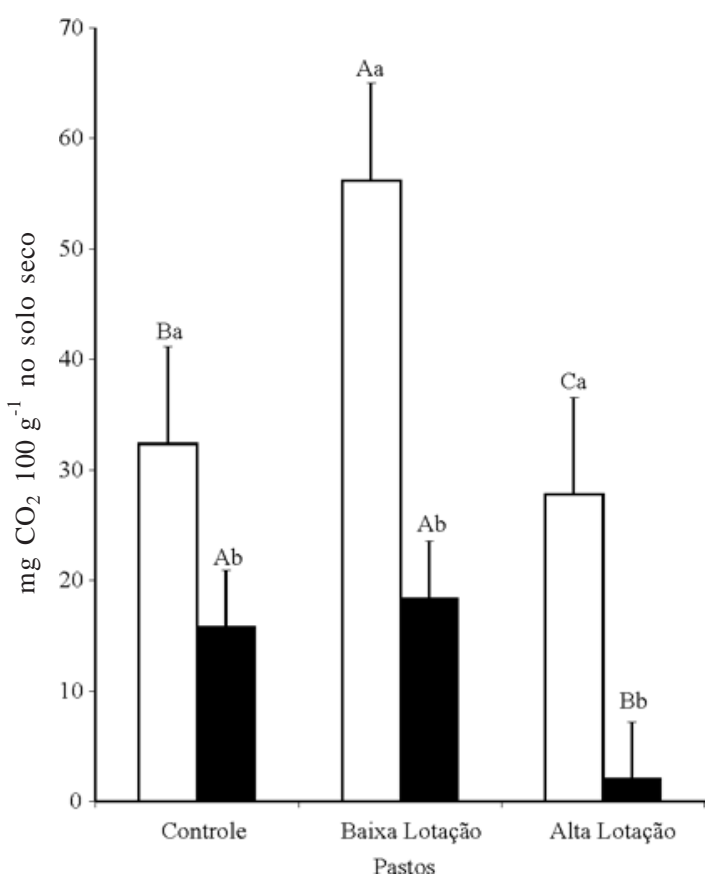

Figura 2. Atividade respiratória encontrada nas camadas de $0-10 \mathrm{~cm}(\square)$ e $10-20 \mathrm{~cm}(\square)$ do solo pastejado por ovinos. Médias seguidas de mesma letra, minúscula (profundidade) e maiúscula (pastos), dentro de cada variável, não diferem entre si pelo teste de Tukey a $5 \%$. As barras representam o erro-padrão $(n=15)$. 
Quadro 2. Nitrogênio total, carbono orgânico e matéria orgânica dos solos pastejados por ovinos ${ }^{(1)}$

\begin{tabular}{lcccc}
\hline \multicolumn{2}{c}{ Tratamento } & Nitrogênio total & Carbono orgânico & Matéria orgânica \\
\hline \multirow{2}{*}{ Pasto } & & $\mu \mathrm{g} \mathrm{g}^{-1}$ de N no solo seco & $\mathrm{mg} \mathrm{g}^{-1} \mathrm{de} \mathrm{C} \mathrm{no} \mathrm{solo} \mathrm{seco}$ & $\%$ \\
& Controle & $1.288,74 \mathrm{~b}$ & $23,81 \mathrm{~b}$ & $6,17 \mathrm{~b}$ \\
& Baixa Lotação & $2.417,91 \mathrm{a}$ & $28,18 \mathrm{a}$ & $7,74 \mathrm{a}$ \\
Camada & Alta Lotação & $1.007,78 \mathrm{c}$ & $15,48 \mathrm{c}$ & $5,25 \mathrm{c}$ \\
$(\mathrm{cm})$ & $0-10$ & $1.891,91 \mathrm{a}$ & $25,00 \mathrm{a}$ & $5,88 \mathrm{~b}$ \\
Teste F & 10-20 & $1.251,04 \mathrm{~b}$ & $19,98 \mathrm{~b}$ & $0,0001^{* * *}$ \\
& Pasto (P) & $0,0001^{* * *}$ & $0,0001^{* * *}$ & $0,0004^{* *}$ \\
& Camada (C) & $0,0001^{* * *}$ & $0,0001^{* *}$ & $0,0070^{* *}$ \\
\hline
\end{tabular}

(1) Médias seguidas de mesma letra, na coluna e dentro de cada variável, não diferem entre si pelo teste de Tukey a $5 \%$. ${ }^{\text {ns }}$ nãosignificativo. ${ }^{* *} \mathrm{e}^{* * *}$ Significativo a 1 e $0,1 \%$ pelo teste $\mathrm{F}$, respectivamente.

Quadro 3. Correlação entre as variáveis estudadas dos solos pastejados pelos ovinos

\begin{tabular}{lllllllll}
\hline & $\mathbf{C}-\mathbf{C O}_{2}$ & $\mathbf{C B M}$ & $\mathbf{N B M}$ & $\mathbf{C}$ org. & $\mathbf{N O}_{3}{ }^{-}$ & Urease & Protease & N Total \\
\hline $\mathrm{MO}$ & $0,81^{* * *}$ & $0,75^{* * *}$ & $0,61^{* * *}$ & $0,74^{* * *}$ & $0,87^{* * *}$ & $0,76^{* * *}$ & $0,84^{* * *}$ & $0,90^{* * *}$ \\
$\mathrm{C}-\mathrm{CO}_{2}$ & - & $0,88^{* * *}$ & $0,52^{* *}$ & $0,73^{* * *}$ & $0,75^{* * *}$ & $0,80^{* * *}$ & $0,91^{* * *}$ & $0,84^{* * *}$ \\
$\mathrm{CBM}$ & - & - & $0,59^{* *}$ & $0,51^{* *}$ & $0,71^{* * *}$ & $0,90^{* * *}$ & $0,92^{* * *}$ & $0,83^{* * *}$ \\
$\mathrm{NBM}$ & - & - & - & $0,51^{* *}$ & $0,70^{* * *}$ & $0,53^{* *}$ & $0,61^{* * *}$ & $0,66^{* * *}$ \\
$\mathrm{C}$ org. & - & - & - & - & $0,66^{* * *}$ & $0,56^{* *}$ & $0,68^{* * *}$ & $0,71^{* * *}$ \\
$\mathrm{NO} \mathrm{S}_{3}$ & - & - & - & - & - & $0,72^{* * *}$ & $0,79^{* * *}$ & $0,88^{* * *}$ \\
Urease & - & - & - & - & - & - & $0,88^{* * *}$ & $0,87^{* * *}$ \\
Prot. & - & - & - & - & - & - & - & $0,89^{* * *}$
\end{tabular}

** e ***: significativo a, respectivamente, 1 e $0,1 \%$. MO: matéria orgânica; C- $\mathrm{CO}_{2}$ : atividade respiratória; CBM: carbono da biomassa microbiana; NBM - nitrogênio da biomassa Microbiana; C org.: C orgânico.

As atividades da urease variaram de 63,0 a $1.550,8 \mu \mathrm{g} \mathrm{g} \mathrm{g}^{-1}$ de $\mathrm{NH}_{4}-\mathrm{N}$ no solo seco (Figura 4), enquanto as da protease variaram de 922,1 a 3.075,64 $\mu \mathrm{g} \mathrm{g}^{-1}$ de tirosina no solo seco (Figura 5). Essa variação correspondeu a aumento significativo de 7,7 vezes na atividade da urease no solo sob pastos com baixa $\mathrm{LO}$ e de 2,2 a 4,8 vezes na da protease encontrada na camada de $0-10$, em relação à de $10-20 \mathrm{~cm}$. Também, a atividade da urease foi maior no controle do que no solo sob pastos com alta LO. Houve diminuição significativa da atividade proteolítica na seguinte ordem: pastos com baixa LO > controle > pastos com alta LO. Confirmando esses resultados, a diminuição das atividades da protease e da urease tem sido relatada em solos sob pastos na ausência de animais (Saviozzi et al., 2002; Bol et al., 2003).

A redução das atividades de urease e protease em pastos com alta LO sugere que o potencial de mineralização do $\mathrm{N}$ pode estar sendo afetado pela disponibilidade deste elemento. Como o $\mathrm{N}$ é um nutriente limitante da produção agrícola, a redução da atividade enzimática pode indicar efeito deletério no crescimento da pastagem (Arunachalam et al., 1999).

A variação dos conteúdos de C orgânico, matéria orgânica e $\mathrm{N}$ total seguiu a mesma tendência anteriormente verificada com a atividade enzimática, mostrando significativo decréscimo com a camada do solo e efeito da taxa de LO (Quadro 2). A variação devida à taxa de LO foi na seguinte ordem: solos sob pastos com baixa $\mathrm{LO}>$ controle $>$ pastos com alta LO. Portanto, o aumento do C orgânico, da matéria orgânica e do $\mathrm{N}$ total em pastos com baixa LO pode ser atribuído às excreções dos animais. Em adição, pastos com alta LO tiveram diminuição no C orgânico e $\mathrm{N}$ total, possivelmente em decorrência da maior 


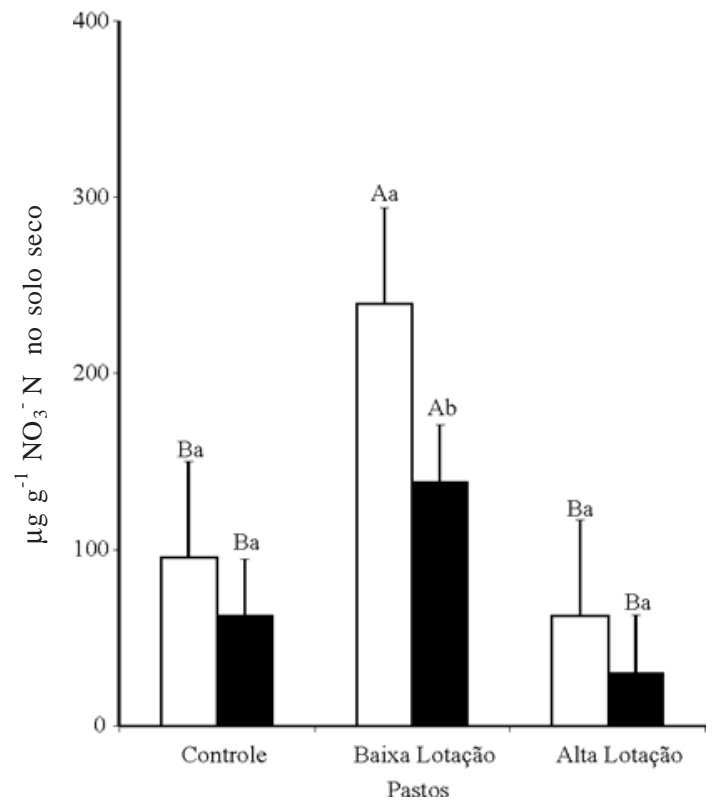

Figura 3. Atividade nitrificante encontrada nas camadas de 0-10 ( $\square$ ) e 10-20 cm (口) do solo pastejado por ovinos. Médias seguidas de mesma letra, minúscula (profundidade) e maiúscula (pastos), dentro de cada variável, não diferem entre si pelo teste de Tukey a $5 \%$. As barras representam o erro-padrão $(n=15)$.

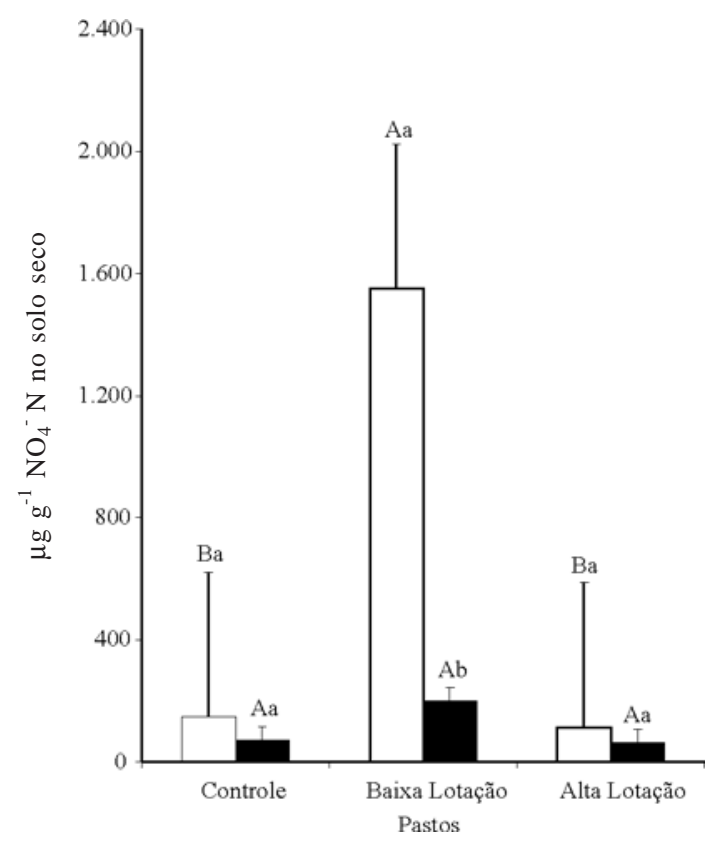

Figura 4. Atividade ureolítica encontrada nas camadas de 0-10 ( $\square$ ) e 10-20 cm (口) do solo pastejado por ovinos. Médias seguidas de mesma letra, minúscula (profundidade) e maiúscula (pastos), dentro de cada variável, não diferem entre si pelo teste de Tukey a $5 \%$. As barras representam o erro-padrão $(n=15)$.

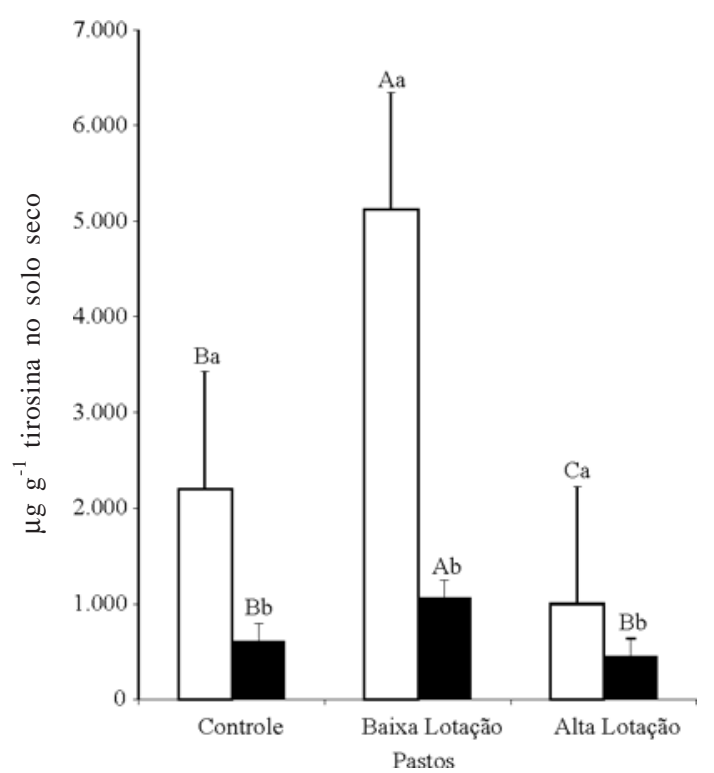

Figura 5. Atividade proteolítica encontrada nas camadas de 0-10 ( $\square$ ) e 10-20 cm (口) do solo pastejado por ovinos. Médias seguidas de mesma letra, minúscula (profundidade) e maiúscula (pastos), dentro de cada variável, não diferem entre si pelo teste de Tukey a $5 \%$. As barras representam o erro-padrão $(n=15)$.

velocidade de decomposição da matéria orgânica. Mineralização intensa tem ocasionado perda de nutrientes da matéria orgânica do solo (Unkovich et al., 1998).

As quantidades de matéria orgânica e de nutrientes podem também evidenciar efeito pronunciado da freqüência de ovinos nas características microbianas e químicas. Enquanto os pastos controle e de baixa LO tinham cobertura vegetal homogênea, os pastos com alta LO apresentaram falhas com parte do solo exposto. O trânsito animal intenso acarreta compactação localizada e falha na vegetação. Os ovinos pastejam ao nível do solo, retirando a grama na base da planta; dessa forma, quando em uma freqüência alta de lotação, causam excessiva diminuição da vegetação e da rebrota (Bishop-Hurley, 2000). Vegetação descontínua e intensa mineralização podem ter acarretado a diminuição das variáveis estudadas nos pastos com alta LO. Por isso, a disponibilidade de nutrientes das excreções animais e dos resíduos vegetais é prejudicada, diminuindo o conteúdo de $\mathrm{C}$ e $\mathrm{N}$ do solo. Resultados semelhantes foram encontrados por Wright et al. (2004), que relataram redução do C e $\mathrm{N}$ orgânicos do solo em pasto com alta lotação de bovinos. Além do mais, falhas na vegetação devido à alta LO podem ocasionar maior perda de umidade do solo do que pastos com baixa LO (Holt, 1997), limitando o crescimento microbiano.

Sarathchandra et al. (1984) relataram que a biomassa microbiana e as atividades nitrificante e das 
enzimas como urease, protease, fosfatase e sulfatase estão relacionadas com o conteúdo de matéria orgânica do solo em pastagens na Austrália. Esse efeito foi encontrado neste estudo (Quadro 3), que mostra correlação positiva e significativa dos conteúdos de $\mathrm{C}$ orgânico, matéria orgânica e $\mathrm{N}$ total com CBM, NBM e as atividades respiratória, nitrificante, ureolítica e proteolítica. Respostas semelhantes foram relatadas por Paz et al. (2002), que encontraram correlação significativa do conteúdo de C orgânico com os conteúdos de $\mathrm{N}$ total e com as atividades respiratória e enzimática da urease e protease

Todas as avaliações microbianas diminuíram sua atividade com o aumento da profundidade do solo. Esses resultados foram semelhantes aos encontrados por Haynes (1999), estudando pastagens na Nova Zelândia, que relataram diminuição do $\mathrm{C}$ orgânico, do CBM e da atividade da protease da camada de 0-2,5 para $2,5-5,0 \mathrm{~cm}$. Da mesma forma, CBM, NBM e as atividades respiratória e da urease diminuíram da camada de 0-10 para a de 10-20 cm (Fernandes et al., 2005). A resposta obtida neste trabalho é uma evidente conseqüência da diminuição do C orgânico, da matéria orgânica e do $\mathrm{N}$ total com a profundidade do solo, como foi observado pela alta correlação $(\mathrm{p}<0,01)$ entre as variáveis estudadas (Quadro 3). Portanto, em razão do maior acúmulo superficial de matéria orgânica, fezes e urina, o potencial de mineralização da matéria orgânica do solo, assim como a atividade respiratória, diminuiu com o aumento da profundidade. A compactação do solo pelos animais não deve ter influído na transferência da matéria orgânica e de nutrientes, porque o efeito da profundidade foi também observado na ausência de animais.

\section{CONCLUSÕES}

1. Pastos com baixa lotação de ovinos propiciaram o maior aumento da biomassa microbiana e das atividades respiratória, nitrificante e enzimática do solo.

2. Pastos com alta lotação de ovinos apresentaram a menor quantidade de vegetação e diminuição nas suas propriedades químicas e microbianas.

3 . Solo da camada superficial $(0-10 \mathrm{~cm})$ tende a acumular matéria orgânica e nutrientes químicos, acarretando aumento da biomassa e atividade microbiana.

\section{AGRADECIMENTOS}

À FUNDUNESP - Fundação para o Desenvolvimento da UNESP, pelo auxílio financeiro ao projeto, e à Fundação Agrisus (MRLG) e ao CNPq (EN), pelas bolsas concedidas.

\section{LITERATURA CITADA}

ALLEN, A.G.; JARVIS, S.C. \& HEADON, D.M. Nitrous oxide emissions from soils due to inputs of nitrogen from excreta return by livestock on grazed grassland in the U.K. Soil Biol. Biochem., 28:597-607, 1996.

ARUNACHALAM, K.; ARUNACHALAM, A. \& MELKANIA, N.P. Influence of soil properties on microbial populations, activity and biomass in humid subtropical mountainous ecosystems of India. Biol. Fertil. Soils, 30:217-223, 1999.

BISHOP-HURLEY, G.J. Growth of pasture plants. In: BISHOPHURLEY, G.J.; HAMILTON, S.A. \& KALLENBACH, R., eds. Missouri dairy grazing manual. Columbia, University of Missouri, Missouri University Extension, 2000.

BOL, R.; KANDELER, E.; AMELUNG, W.; GLASER, B.; MARX, M.C.; PREEDY, N. \& LORENZ, K. Short-term effects of dairy slurry amendment on carbon sequestration and enzyme activities in a temperature grassland. Soil Biol. Biochem., 35:1411-1421, 2003.

BREMNER, J.M. \& MULVANEY, C.S. Nitrogen-total. In: PAGE, A.L.; MILLER, R.H. \& KEENEY, D.R., eds. Methods of soil analysis: Chemical and microbiological properties. 2.ed. Madison, American Society of Agronomy, 1982. Part 2. p.595-624.

BROOKES, P.C.; LANDMAN, A.; PRUDEN, G. \& JENKINSON, D.S. Chloroform fumigation and the release of soil nitrogen: a rapid extraction method to measure microbial biomass nitrogen in soil. Soil Biol. Biochem., 17:837-842, 1985.

CAMERON, M.D. Field study of gross rates of $\mathrm{N}$ mineralization and nitrification and their relationships to microbial biomass and enzyme activities in soils treated with dairy effluent and ammonium fertilizer. Soil Use Manag., 15:188-194, 1999 .

CARRAN, R.A. \& THEOBALD, P.W. Effects of excreta return on properties of a grazed pasture soil. Nutr. Cycling Agroecosys., 56:79-85, 2000.

CASTRO, A.B.; NEIVA, J.N.M.; OLIVEIRA, T.S. \& ALVES, A.A. Desempenho produtivo de ovinos mantidos em sistemas silvipastoril (coqueiro) no litoral cearense. In: REUNIÃO ANUAL DA SOCIEDADE BRASILEIRA DE ZOOTECNIA, 40., Santa Maria, 2003. Anais. Santa Maria, 2003. p.1-4.

DE BOER, W.; DUYTS, H. \& LAANBROEK, H.J. Autotrophic nitrification in a fertilized acid heath soil. Soil Biol. Biochem., 20:845-850, 1988.

EMPRESA BRASILEIRA DE PESQUISA AGROPECUÁRIA EMBRAPA. Sistema Brasileiro de Classificação do Solo. Rio de Janeiro, Embrapa/CNPS, 1999. 412p.

FERNANDES, S.A.P.; BETTIOL, W. \& CERRI, C.C. Effect of sewage sludge on microbial biomass, basal respiration, metabolic quotient and soil enzymatic activity. Appl. Soil Ecol., 30:65-77, 2005.

FIALHO, J.F.; BORGES, A.C. \& BARROS, N.F. Cobertura vegetal e as características químicas e físicas e atividade da microbiota de um Latossolo Vermelho-Amarelo distrófico. R. Bras. Ci. Solo, 15:21-28, 1991. 
GAMA-RODRIGUES, E.F. Biomassa microbiana e ciclagem de nutrientes. In: SANTOS, G.A. \& CAMARGO, F.A.O., eds. Fundamentos da matéria orgânica do solo. Porto Alegre, Gênesis, 1999. p.227-243.

GHANI, A.; DEXTER, M. \& PERROTT, K.W. Hot-water extractable carbon in soils: a sensitive measurement for determining impacts of fertilisation, grazing and cultivation. Soil Biol. Biochem., 35:1231-1243, 2003.

HAYNES, R.J. Size and activity of the soil microbial biomass under grass and arable management. Biol. Fertil. Soils, 30:210-216, 1999.

HAYNES, R.J. \& WILLIAMS, P.H. Influence of stock camping behavior on the soil microbiological and biochemical properties of grazed pastoral soils. Biol. Fertil. Soils, 28:253$258,1999$.

HOLT, J.A. Grazing pressure and soil carbon, microbial biomass and enzyme activities in semi-arid northeastern Australia. Appl. Soil Ecol., 5:143-149, 1997.

KEENEY, D.R. \& NELSON, D.W. Nitrogen-inorganic forms. Methods of soil analysis, chemical and microbiological properties. 2.ed. Madison, American Society of Agronomy, 1982. Part 2. p.643-698

Mc GARITY, J.W. \& MYERS, M.G. A survey of urease activity in soils of Northern South Wales. Plant Soil, 27:217-238, 1967.

MUELLER, C.; STEVENS, R.J. \& LAUGHLIN, R.J. Evidence of carbon stimulated $\mathrm{N}$ transformations in grassland soil after slurry application. Soil Biol. Biochem., 35:285-293, 2003.

NANNIPIERI, P.; PEDRAZZINI, F.; ARCARA, P.G. \& PIOVANELLI, C. Changes in amino acids, enzyme activities, and biomasses during soil microbial growth. Soil Sci., 127:26-34, 1979.

PAZ, J.M.; HORRA, A.M.; PRUZZO, L. \& PALMA, R.M. Soil quality: A new index based on microbiological and biochemical parameters. Biol. Fertil. Soils, 35:302-306, 2002 .

RAIJ, B. van \& QUAGGIO, J.A. Métodos de análises de solos para fins de fertilidade. Campinas, Instituto Agronômico, 1983. 31p. (Boletim Técnico, 81)

REZENDE, L.A.; ASSIS, L.C. \& NAHAS, E. Carbon, nitrogen and phosphorus mineralization in two soils amended with distillery yeast. Biores. Technol., 94:159-167, 2004.
ROSS, D.J; SPEIR, T.W.; KETTLES, H.A. \& MACKAY, A.D. Soil microbial biomass, $\mathrm{C}$ and $\mathrm{N}$ mineralization and enzyme activities in a hill pasture: influence of season and slow-release P and S fertilizer. Soil Biol. Biochem., 27:1431-1439, 1995.

SARATHCHANDRA, S.U.; PERROTT, K. W. \& UPSDELL, M.P. Microbiological and biochemical characteristics of a range of New Zealand soils under established pasture. Soil Biol. Biochem., 16:177-183, 1984.

SAS INSTITUTE. Statistical Analysis System, SAS/STAT use's guide V.6. 3.ed. Cary, 1990. 705p.

SAVIOZZI, A.; BUFALINO, P.; LEVI-MINZI, R. \& RIFFALDI, R. Biochemical activities in a degraded soil restored by two amendments: A laboratory study. Biol. Fertil. Soils, 35:96-101, 2002.

SAVIOZZI, A.; LEVI-MINZI, R.; CARDELLI, R. \& RIFFALDI, R. A comparison of soil quality in adjacent cultivated, Forest and native grassland soils. Plant Soil, 233:251-259, 2001.

SCHMIDT, E.L. \& BELSER, L.W. Autotrophic nitrifying bacteria. In: WEAVER, R.W.; ANGLE, S.; BOTTOMLEY, D.; BEZDICEK, D.; SMITH, S. TABATABAI, A. \& WOLLUM, A., eds. Methods of soils analysis. Microbiological and biochemical properties. Madison, Soil Science Society of America, 1994. p.159-177. Part 2. (SSSA Book Series, 5)

SILVA SOBRINHO, A.G. Criação de ovinos. 2.ed. Jaboticabal, Funep, 2001. 302p.

SIMS, J.R. \& HABY, V.A. Simplified colorimetric determination of soil organic matter. Soil Sci.., 112:137 - 141, 1971.

STAMATIADIS, S.; DORAN, J.W. \& KETTLER, T. Field and laboratory evaluation of soil quality changes resulting from injection of liquid sewage sludge. Appl. Soil Ecol., 12:263-272, 1999.

UNKOVICH, M.P.; SANDORD, J.P. \& HYDER, M. Effects of grazing on plant and soil nitrogen relations of pasturecrop rotations. Aust. J. Agric. Res., 49:475-485, 1998.

VANCE, E.D., BROOKES, P.C. \& JENKINSON, D.S. An extraction method for measuring soil microbial biomass C. Soil Biol. Biochem., 19:703-707, 1987.

WRIGHT, A.L.; HONS, F.M. \& ROUQUETTE Jr., F.M. Longterm management impacts on soil carbon and nitrogen dynamics of grazed bermudagrass pastures. Soil Biol. Biochem., 36:1809-1816, 2004. 